\title{
Fusion genes and rearranged genes as a linear function of chromosome aberrations in cancer
}

\author{
Felix Mitelman, Bertil Johansson \& Fredrik Mertens
}

\begin{abstract}
Cytogenetic aberrations have been reported in 45,000 human neoplasms. Structural balanced rearrangements are associated with distinct tumor subtypes with remarkable specificity and have been essential for identifying genes involved in tumorigenesis ${ }^{1,2}$. All balanced rearrangements that have been characterized molecularly act by deregulating a gene in one of the breakpoints or by creating a fusion gene ${ }^{3-6}$. Because most recurrent aberrations and rearranged genes have been found in hematological disorders, whereas numerous genomic imbalances have been identified in solid tumors ${ }^{7,8}$, it has become generally accepted that there are pathogenetic differences between these neoplasms. We here show that in every tumor type, the numbers of recurrent balanced chromosome abnormalities, fusion genes and genes rearranged as a consequence of balanced aberrations are simply a function of the number of cases with an abnormal karyotype. Hence, there may not be any fundamental tissue-specific differences in the genetic mechanisms by which neoplasia is initiated.
\end{abstract}

We surveyed all 44,750 cytogenetically abnormal neoplasms reported in the literature up to December 2003 (Mitelman Database of Chromosome Aberrations in Cancer, see URL below) and retrieved all recurrent balanced structural aberrations (i.e., those present in at least two cases of the same morphology). For epithelial tumors, we also required that they be located in the same organ. Only well-characterized structural abnormalities were included; aberrations involving unidentified chromosomal regions or having uncertain breakpoints were excluded. We then systematically ascertained all fusion genes and genes rearranged as a consequence of a balanced chromosome change.

\begin{abstract}
Assessment of available data
Among the nine main neoplastic entities for which more than 1,000 cases with an abnormal karyotype had been reported, we identified 463 different recurrent balanced aberrations (Table 1). The published data are heavily biased in favor of the hematological malignancies, which constituted $74 \%$ of the cases; all solid tumors made up only $26 \%$. Likewise, 363 of 463 (78\%) recurrent balanced aberrations were present in the former group. Whereas 68 of 363 (19\%) of the recurrent aberrations were shared by different hematological malignancies, only
\end{abstract}

The authors are in the Department of Clinical Genetics, University Hospital, SE22185 Lund, Sweden. e-mail: felix.mitelman@klingen.lu.se

Published online 30 March 2004; doi:10.1038/ng1335
4 of 111 (4\%) recurrent aberrations among mesenchymal and epithelial tumors were shared (Table 1). Furthermore, only 11 of all 463 (2\%) recurrent aberrations were found in both hematological disorders and solid tumors. There was a highly significant correlation between the number of recurrent balanced aberrations within each tumor category and the number of cases with an abnormal karyotype (Fig. 1a).

We identified 271 fusion genes and 59 potential fusion genes in which only one of the two breakpoints had been cloned. A substantial proportion of the genes recombine with several partner genes (e.g., ETV6, EWSR1, MLL and RET), making the number of rearranged genes smaller than might be expected from the number of fusion genes. We identified 275 unique genes (Table 2). Both the number of fusion genes (Fig. 1b) and the number of rearranged genes (Fig. 1c) in each tumor category were strictly proportional to the number of cases with an abnormal karyotype.

Not only are the proportions of fusion genes and rearranged genes equal among the different tumor entities, but also the general biological properties of the involved genes do not seem to differ. Although most gene classes are too small to allow detailed statistical comparisons, the fraction of genes belonging to the dominating class, transcription control genes (Table 2), is clearly similar among the hematological disorders (38\%, 77 of 205) and the solid tumors (44\%, 38 of 87 ), with no significant difference between mesenchymal and epithelial tumors. The second most common class, tyrosine kinases, is also equally involved (5-7\%) in the hematological disorders, mesenchymal tumors and epithelial tumors. In addition, several genes, such as ETV6, EWSR1 and HMGA2 (Table 2), are rearranged in all three subgroups, and one particular fusion gene, ETV6-NTRK3, has been described in entities as diverse as acute myeloid leukemia (AML), infantile fibrosarcoma, mesoblastic nephroma and breast carcinoma ${ }^{9-12}$. These data strengthen the conclusion from the quantitative comparisons presented above that there are no fundamental tissuespecific differences.

\section{Conceptual and analytical problems}

Overwhelming evidence supports the hypothesis that the neoplastic phenotype is caused by a stepwise accumulation of a number of genetic and epigenetic alterations ${ }^{13,14}$. The role of genomic instability as a mechanism to initiate or promote this genetic variation is still controversial $^{15-18}$, as is the question of whether there is a distinctive difference between different tumor types depending on whether the initiating event is a mutation leading to loss of function of tumor suppressor genes ${ }^{19}$ or deregulation or fusion of genes as a consequence of 
Table 1 Number of cases with acquired abnormal karyotypes, recurrent balanced aberrations, fusion genes and rearranged genes

\begin{tabular}{|c|c|c|c|c|}
\hline Tumor type & Abnormal karyotypes & Recurrent balanced aberrations & Fusion genes & Rearranged genes \\
\hline \multicolumn{5}{|l|}{ Hematological malignancies } \\
\hline Acute myeloid leukemia (AML) & 10,718 & 126 & 86 & 97 \\
\hline Acute lymphoblastic leukemia (ALL) & 6,497 & 112 & 62 & 69 \\
\hline Chronic myeloproliferative disorders (CMD) a & 3,566 & 28 & 22 & 30 \\
\hline Myelodysplastic syndromes (MDS) & 3,569 & 27 & 22 & 32 \\
\hline B-cell malignant lymphomas (B-ML) & 5,295 & 104 & 49 & 52 \\
\hline Plasma cell dyscrasias (PCD) & 1,209 & 17 & 13 & 17 \\
\hline T-cell malignant lymphomas (T-ML) & 1,047 & 17 & 16 & 27 \\
\hline Total hematological malignancies & 31,901 & 363 & 209 & 205 \\
\hline \multicolumn{5}{|l|}{ Solid tumors } \\
\hline Mesenchymal tumors (MT) ${ }^{\mathrm{b}}$ & 5,011 & 54 & 38 & 50 \\
\hline Epithelial tumors $(E T)^{c}$ & 6,246 & 61 & 29 & 46 \\
\hline Total solid tumors & 11,257 & 111 & 64 & 87 \\
\hline All neoplasms & 43,158 & 463 & 271 & 275 \\
\hline
\end{tabular}

ancludes $\mathrm{t}(9 ; 22)$-positive chronic myeloid leukemia; variant translocations not included among the recurrent aberrations. ${ }^{\mathrm{b}}$ Includes neuroglial tumors. ${ }^{\mathrm{C}}$ Includes melanocytic neoplasms.

balanced cytogenetic aberrations ${ }^{3-6}$. This distinction is conceptually important. It is generally believed that the former mechanism, triggered or maintained by genomic instability, operates predominantly in epithelial tumors, whereas the latter predominates in hematological disorders and mesenchymal tumors ${ }^{8,20}$. This view seems to be based on reports of numerous specific cytogenetic aberrations and genes rearranged as a result of chromosome changes in hematological malignancies and in bone and soft tissue tumors. In contrast, such aberrations seem to be rare among epithelial tumors, in which attention is instead focused on gene mutations and deletions. Consequently, functional abrogation of tumor suppressor genes is increasingly regarded as a preferred initiating event in epithelial tumorigenesis $8,14,16,18$.

Our results show that this prevailing opinion may be based on a selective interpretation of the available data. The biased view may, to a large extent, be due to the fact that cytogenetic analyses suffer from several quantitative and qualitative shortcomings. First, because of technical problems, the chromosome morphology of solid tumors in general, and epithelial tumors in particular, is often poor, and as a consequence, many of the published solid tumors have been only partially karyotyped. Second, even when the quality is good, the karyotypes are usually so complex that it is practically impossible to characterize them in detail. This means that a very large number of cases of any particular tumor entity will have to be studied before the pathogenetically important aberration(s) can be distinguished from the confusing variety of secondary, progression-related changes. Third, and particularly applicable to epithelial tumors, clonal heterogeneity in the form of cytogenetically unrelated clones ${ }^{21,22}$ introduces a further dimension of complexity and poses important analytical problems. a

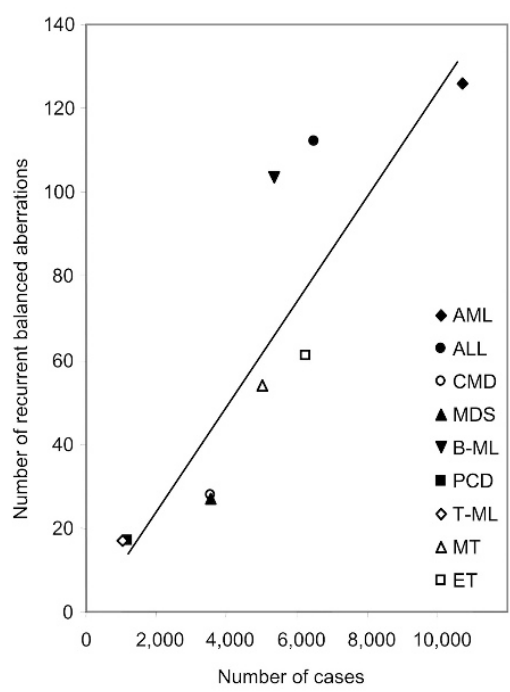

b

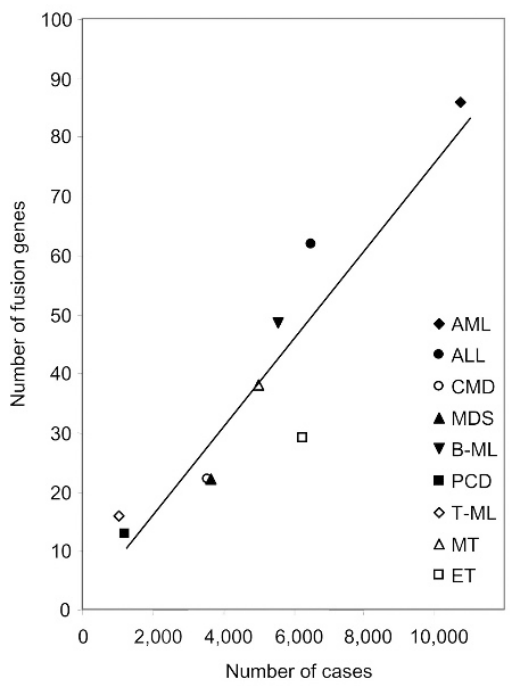

C

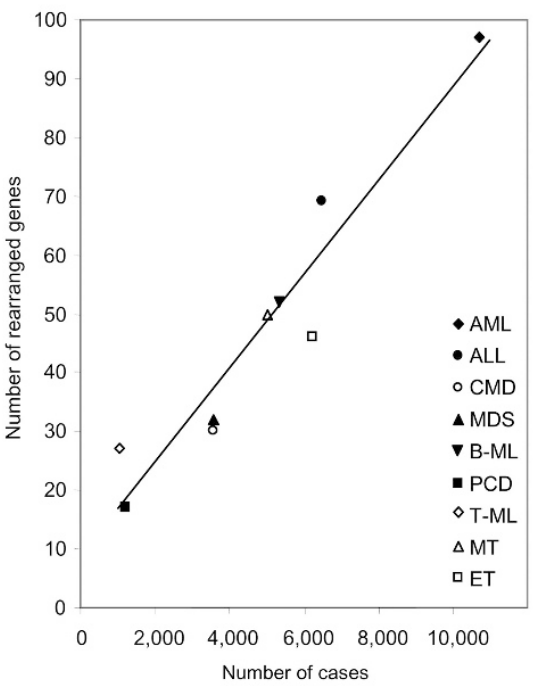

Figure 1 Numbers of recurrent balanced chromosomal aberrations, fusion genes and rearranged genes as a consequence of balanced cytogenetic abnormalities in relation to number of reported cases with an abnormal karyotype in tumors of each type. (a) Balanced aberrations (adjusted $\mathrm{R}^{2}=74 \%$, $P=0.0019$ ). (b) Fusion genes (adjusted $\mathrm{R}^{2}=82 \%, P<0.001$ ). (c) Rearranged genes (adjusted $\mathrm{R}^{2}=90 \%, P<0.0001$ ). For abbreviations, see Table 1 . 
Table 1 Number of cases with acquired abnormal karyotypes, recurrent balanced aberrations, fusion genes and rearranged genes

\begin{tabular}{|c|c|c|c|c|}
\hline Tumor type & Abnormal karyotypes & Recurrent balanced aberrations & Fusion genes & Rearranged genes \\
\hline \multicolumn{5}{|l|}{ Hematological malignancies } \\
\hline Acute myeloid leukemia (AML) & 10,718 & 126 & 86 & 97 \\
\hline Acute lymphoblastic leukemia (ALL) & 6,497 & 112 & 62 & 69 \\
\hline Chronic myeloproliferative disorders (CMD) a & 3,566 & 28 & 22 & 30 \\
\hline Myelodysplastic syndromes (MDS) & 3,569 & 27 & 22 & 32 \\
\hline B-cell malignant lymphomas (B-ML) & 5,295 & 104 & 49 & 52 \\
\hline Plasma cell dyscrasias (PCD) & 1,209 & 17 & 13 & 17 \\
\hline T-cell malignant lymphomas (T-ML) & 1,047 & 17 & 16 & 27 \\
\hline Total hematological malignancies & 31,901 & 363 & 209 & 205 \\
\hline \multicolumn{5}{|l|}{ Solid tumors } \\
\hline Mesenchymal tumors (MT) ${ }^{\mathrm{b}}$ & 5,011 & 54 & 38 & 50 \\
\hline Epithelial tumors $(E T)^{c}$ & 6,246 & 61 & 29 & 46 \\
\hline Total solid tumors & 11,257 & 111 & 64 & 87 \\
\hline All neoplasms & 43,158 & 463 & 271 & 275 \\
\hline
\end{tabular}

ancludes $\mathrm{t}(9 ; 22)$-positive chronic myeloid leukemia; variant translocations not included among the recurrent aberrations. ${ }^{\mathrm{b}}$ Includes neuroglial tumors. ${ }^{\mathrm{C}}$ Includes melanocytic neoplasms.

balanced cytogenetic aberrations ${ }^{3-6}$. This distinction is conceptually important. It is generally believed that the former mechanism, triggered or maintained by genomic instability, operates predominantly in epithelial tumors, whereas the latter predominates in hematological disorders and mesenchymal tumors ${ }^{8,20}$. This view seems to be based on reports of numerous specific cytogenetic aberrations and genes rearranged as a result of chromosome changes in hematological malignancies and in bone and soft tissue tumors. In contrast, such aberrations seem to be rare among epithelial tumors, in which attention is instead focused on gene mutations and deletions. Consequently, functional abrogation of tumor suppressor genes is increasingly regarded as a preferred initiating event in epithelial tumorigenesis $8,14,16,18$.

Our results show that this prevailing opinion may be based on a selective interpretation of the available data. The biased view may, to a large extent, be due to the fact that cytogenetic analyses suffer from several quantitative and qualitative shortcomings. First, because of technical problems, the chromosome morphology of solid tumors in general, and epithelial tumors in particular, is often poor, and as a consequence, many of the published solid tumors have been only partially karyotyped. Second, even when the quality is good, the karyotypes are usually so complex that it is practically impossible to characterize them in detail. This means that a very large number of cases of any particular tumor entity will have to be studied before the pathogenetically important aberration(s) can be distinguished from the confusing variety of secondary, progression-related changes. Third, and particularly applicable to epithelial tumors, clonal heterogeneity in the form of cytogenetically unrelated clones ${ }^{21,22}$ introduces a further dimension of complexity and poses important analytical problems. a

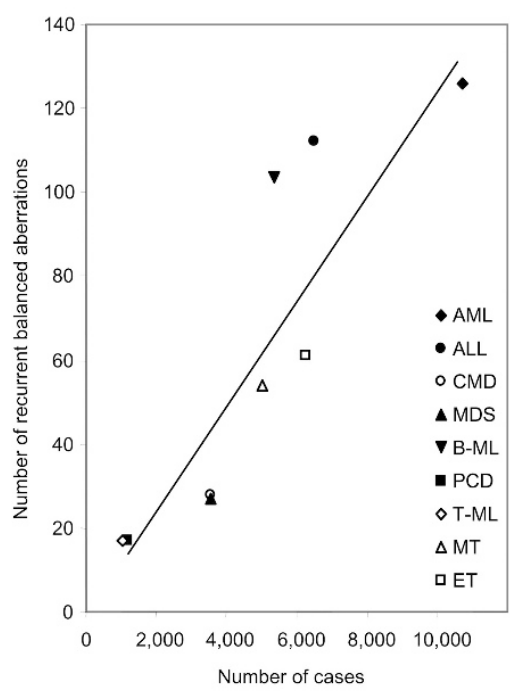

b

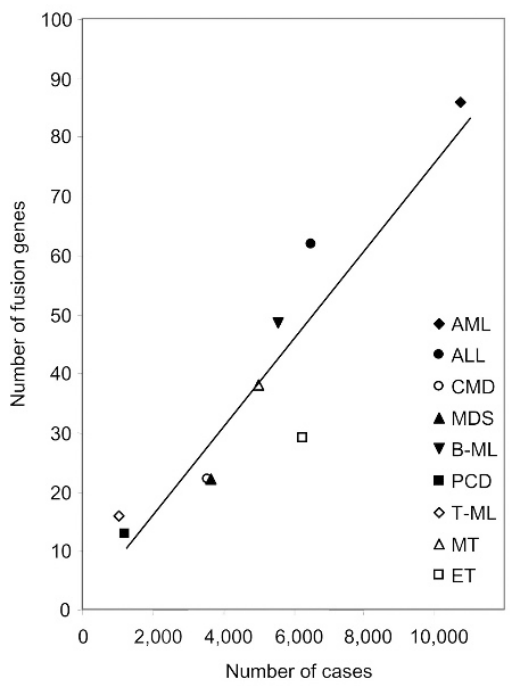

C

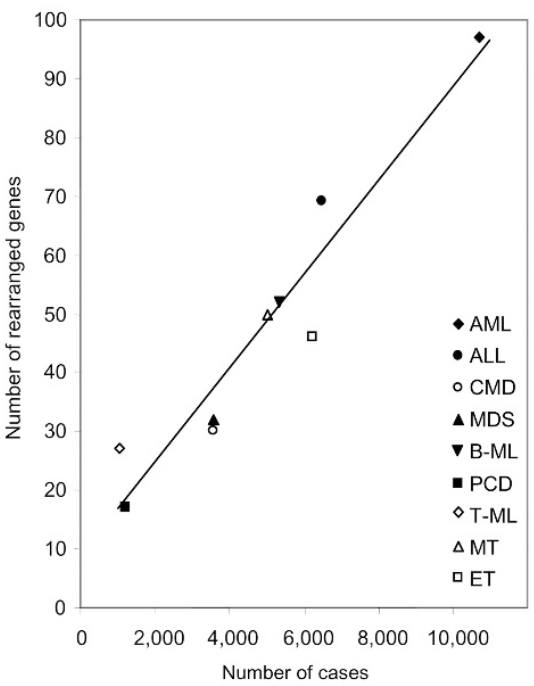

Figure 1 Numbers of recurrent balanced chromosomal aberrations, fusion genes and rearranged genes as a consequence of balanced cytogenetic abnormalities in relation to number of reported cases with an abnormal karyotype in tumors of each type. (a) Balanced aberrations (adjusted $\mathrm{R}^{2}=74 \%$, $P=0.0019$ ). (b) Fusion genes (adjusted $\mathrm{R}^{2}=82 \%, P<0.001$ ). (c) Rearranged genes (adjusted $\mathrm{R}^{2}=90 \%, P<0.0001$ ). For abbreviations, see Table 1 . 
Table 2 Genes rearranged as a consequence of acquired balanced cytogenetic aberrations in neoplasia

\begin{tabular}{|c|c|c|c|c|c|}
\hline$A B L 1^{\mathrm{a}} \diamond \bigcirc \bigcirc \Delta \nabla \mathbf{\Delta}$ & $C L T C L 1 \diamond$ & GRAF & $M A L T 1 \nabla \mathbf{\square}$ & $P A X \not D \triangle$ & $S S X 4^{\mathrm{b}} \triangle$ \\
\hline$A B L 2^{\mathrm{a}} \diamond \mathbf{0}$ & CMKOR1 $\triangle$ & GSTP1 $\bigcirc$ & $M A M L 2^{\mathrm{b}} \square$ & PAX $\square$ & $S T L$ \\
\hline ACSL6 & COL1A1 $\triangle$ & HAS2 $\triangle$ & $M D S 1^{\mathrm{b}} \diamond \bigcirc \boldsymbol{\Delta}$ & $P B X 1^{\mathrm{b}} \diamond \mathbf{O}$ & $S Y K^{a} \boldsymbol{\Lambda}$ \\
\hline$A F 1 Q$ & COL1A2 $\triangle$ & $H E A B \bullet$ & MDS2 $\Delta$ & $P C M 1 \square$ & $T A F 15^{b} \bullet \bigcirc \triangle$ \\
\hline$A F 5 A \bullet$ & $\operatorname{cox} 6 C \triangle \triangle$ & $H E R V K \bigcirc$ & MECT1 $\square$ & PCSK7 $\nabla$ & $T A L 1^{\mathrm{b}} \bigcirc \square$ \\
\hline AF5Q31T⿱ & $C R E B B P^{b} \wedge \mathbf{O A}^{\Delta}$ & HIPI $\boldsymbol{\Delta}$ & MHC2TA $\boldsymbol{\nabla}$ & $P D G F B \boldsymbol{\nabla} \triangle$ & $T A L 2^{\mathrm{b}}$ \\
\hline$A F 15 Q 14 \diamond 0$ & CSF1 $\bullet$ & HIST1H4I $\mathbf{\nabla}$ & $M K L 1^{b} \bullet$ & PDGFRA ${ }^{\mathrm{a}} \bigcirc$ & $T C E A 1^{\mathrm{b}} \square$ \\
\hline$A L K^{\mathrm{a}} \diamond \nabla \diamond \triangle$ & CSF2 $\bullet$ & $H L F^{D} \bigcirc$ & $M L F 1 \diamond$ & $P D G F R B^{\mathrm{a}} \diamond \bigcirc \wedge$ & $T_{C F} 3^{\mathrm{b}} \bullet$ \\
\hline$A L P H A \square$ & CSF3 $\bigcirc$ & $H L X B 9^{b} \bullet$ & $M L L^{\mathrm{b}} \diamond \bigcirc \vee \boldsymbol{\nabla} \diamond$ & $P E R 1 \bullet$ & TCF12 $\triangle$ \\
\hline ARHGEF12 & CTNNB1 $\square$ & $H M G A 1^{\mathrm{b}} \triangle \square$ & $M L L T I^{\mathrm{b}} \diamond \mathbf{0}$ & $P I C A L M \diamond \mathbf{\nabla}$ & $T C L 1 A \bigcirc \diamond$ \\
\hline$A R H H \nabla \mathbf{\square}$ & CXXC6 & $H M G A 2^{b} \nabla \triangle \square$ & $M L L T 2^{\mathrm{b}} \bullet$ & PIM1 $\mathbf{\nabla}$ & $T C L 2 \bigcirc$ \\
\hline$A R N T \bullet$ & $D D I T 3^{\mathrm{b}} \triangle$ & $H O X A 9^{b} \diamond \bigcirc \Delta$ & $M L L T 3^{b} \wedge \mathbf{\Delta}$ & $P L A G 1^{\mathrm{b}} \triangle \square$ & TCL6O \\
\hline ASPSCR $1 \triangle \square$ & $D D \times 6 \bigcirc$ & $H O X A 11^{\mathrm{b}} \bigcirc$ & $M L L T 4 \triangleleft 0$ & $P M L^{\mathrm{b}} \bullet$ & TCTA \\
\hline $\operatorname{ATF1}^{\mathrm{b}} \triangle$ & $D D X 10 \diamond \boldsymbol{\Delta}$ & $H O X A 13^{b} \bullet \boldsymbol{\Delta}$ & $M L L T \sigma^{\mathrm{b}} \bullet$ & PNUTL1 $\bullet$ & TFE3 $^{\mathrm{b}} \triangle \square$ \\
\hline$\overline{A T I C} \diamond \triangle$ & $D E K^{b} \diamond \bigcirc \wedge$ & $\mathrm{HOXC11^{ \textrm {b } }} \bullet$ & $M L L T \not \supset \diamond$ & $P O U 2 A F 1^{\mathrm{b}}$ & TFEB $\square$ \\
\hline ATM $\diamond$ & $E L K S \square$ & $\mathrm{HOXC13^{b }} \bullet$ & $M L L T 10^{\mathrm{b}} \bullet \boldsymbol{\nabla}$ & PPARG $\square$ & $T F G \diamond \square$ \\
\hline$B C L 2 \bigcirc \nabla$ & $E L L^{\mathrm{b}} \diamond \boldsymbol{\bullet}^{\Delta}$ & $H O X D 11^{\mathrm{b}} \bullet$ & $M N 1 \diamond \bigcirc \Delta \triangle$ & $P R C C \square$ & TFPT \\
\hline$B C L 3^{\mathrm{b}} \boldsymbol{\nabla}$ & $E P 300^{\mathrm{b}} \bullet$ & HOXD13 & $M S F \bullet$ & $P R D M 16^{\mathrm{b}} \bullet \boldsymbol{\Delta}$ & $\operatorname{TIFI}^{\mathrm{b}} \square$ \\
\hline$B C L 6^{\mathrm{b}} \bigcirc \mathbf{\nabla}$ & EPS15 & $H P R \square$ & $M S I 2 \bigcirc$ & PRKAR1A $\square$ & $T L X 1^{\mathrm{b}} \bigcirc \diamond$ \\
\hline$B C L 7 A \boldsymbol{\nabla}$ & $E R G^{\mathrm{b}} \diamond \triangle$ & HSRNAFEV $\triangle$ & $M T C P 1 \diamond$ & $P R R X 1^{\mathrm{b}} \bullet$ & $T L X 3^{b}$ \\
\hline$B C L 8 \boldsymbol{\nabla}$ & ERVWE1 $\mathbf{\nabla}$ & IGH@ $\mathbf{\nabla} \triangleright$ & $M U C 1 \mathbf{\nabla}$ & $P S I P 1^{\mathrm{b}} \bullet$ & TNFRSF17 $\diamond$ \\
\hline$B C L 9 \bigcirc \mathbf{V}$ & $E T S 1^{\mathrm{b}} \boldsymbol{\nabla}$ & 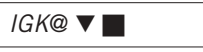 & $M Y B^{\mathrm{b}} \square$ & PVT1 ○ V & $T O P 1 \bullet \boldsymbol{\Lambda}$ \\
\hline$B C L 10 \boldsymbol{\nabla}$ & $E T V 1^{\mathrm{b}} \triangle$ & IGL@○ & $M Y C^{b} \bigcirc \nabla \diamond$ & $R A B E P 1 \boldsymbol{\Delta}$ & TPM3 $\diamond \square$ \\
\hline$B C L 11 A^{\mathrm{b}} \boldsymbol{\nabla}$ & $E T V 4^{\mathrm{b}} \triangle$ & $I L 2 \diamond$ & $M Y H 11 \diamond \bigcirc \Delta$ & $R A D 51 L 1 \triangle$ & $T P M 4 \diamond$ \\
\hline$B C L 11 B^{\mathrm{b}} \bigcirc$ & $E T V \sigma^{\mathrm{b}} \diamond \bigcirc \bigcirc \Delta \nabla \diamond \Delta \square$ & IL21R V & $M Y S T 3^{\mathrm{b}} \bullet \boldsymbol{\Delta}$ & $R A N B P 2 \triangle$ & TPR $\square$ \\
\hline$B C R \diamond \bigcirc \bigcirc \Delta \nabla \square$ & $E V I 1^{\mathrm{b}} \bullet \bigcirc \Delta$ & IL3O & $M Y S T 4^{\mathrm{b}} \bullet \boldsymbol{\Delta}$ & RANBP17@ & $T R A @ \bigcirc \diamond$ \\
\hline$B I R C 3 \nabla \mathbf{\square}$ & $E W S R 1 \bigcirc \square$ & $I R F 1^{\mathrm{b}}$ & $N C K P I S D \diamond$ & RAPIGDS1 & $T R B @ \diamond \diamond \diamond$ \\
\hline BRCA2 \ & FCGR2B $\boldsymbol{\nabla}$ & $I R F 4^{\mathrm{b}} \boldsymbol{\square}$ & NCOA2 & $R A R A^{\mathrm{b}} \bullet$ & $T R D @ \bigcirc$ \\
\hline$B R D 4 \square$ & $F G F R 1^{\mathrm{a}} \bullet \bigcirc$ & $J A K 2^{\mathrm{a}} \bigcirc$ & NCOA4 $\square$ & $R B M 15 \bullet$ & $T R G @ \diamond$ \\
\hline BTG1 $\mathbf{V}$ & $F G F R 1 O P \diamond \bigcirc$ & $J A Z F 1^{\mathrm{b}} \triangle$ & $N F K B 2^{\mathrm{b}} \boldsymbol{\nabla} \mathbf{} \diamond$ & $R E L^{\mathrm{b}} \bigcirc \boldsymbol{\nabla}$ & TRIM33' $\square$ \\
\hline$B V R 1 \boldsymbol{V}$ & $F G F R 3^{\mathrm{a}} \square$ & $J J A Z 1^{\mathrm{b}} \triangle$ & NONO $\square$ & $R E T^{a} \square$ & $T R I P 11^{\mathrm{b}} \bullet$ \\
\hline C12orf9 $\triangle$ & FHIT $\square$ & KIAA1618 $\diamond$ & $\mathrm{NOTCH} 1^{\mathrm{b}}$ & RFG9 $\square$ & $T T L \bigcirc$ \\
\hline CARS $\triangle$ & FIP1L1 $\bigcirc$ & KTN1 $\square$ & $N P M 1 \diamond \nabla \diamond$ & $R O S 1^{\mathrm{a}} \triangle$ & $W H S C 1^{\mathrm{b}} \square$ \\
\hline$C B F A 2 T 1^{\mathrm{b}} \bullet \bigcirc \Delta$ & $F L I 1^{\mathrm{b}} \triangle \square$ & $\angle A F 4^{\mathrm{b}}$ & $N R 4 A 3^{b} \triangle$ & $R P L 22 P 1 \bullet \bigcirc$ & $W T 1^{\mathrm{b}} \triangle$ \\
\hline$C B F A 2 T 3^{\mathrm{b}} \boldsymbol{\Delta}$ & $F N 1 \bullet$ & LAMA4 $\triangle$ & $N R G 1 \square$ & $R P N 1 \bullet \Delta$ & $Z N F 145^{b} \bullet$ \\
\hline$C B F B^{\mathrm{b}} \bullet \bigcirc \Delta$ & $F N B P 1 \bullet$ & $\angle A S P 1 \bullet$ & $N S D 1^{\mathrm{b}} \bullet$ & RPS10 $\square$ & ZNF198 ${ }^{\mathrm{b}} \bigcirc$ \\
\hline$C B L \bullet$ & $F O X 01 A^{\mathrm{b}} \triangle$ & $L C K^{\mathrm{a}} \bigcirc$ & $N T R K 1^{a} \square$ & $R U N X 1^{\mathrm{b}} \diamond \bigcirc \bigcirc$ & $Z N F 278^{b} \triangle$ \\
\hline CCDC6 $\bigcirc \square$ & FOX03A $A^{\mathrm{b}} \bullet$ & $\angle C P 1 \boldsymbol{\nabla}$ & $N T R K 3^{\mathrm{a}} \bullet \triangle \square$ & SEPT6 & ZNF331 ${ }^{\mathrm{b}} \square$ \\
\hline$C C N D 1 \nabla \mathbf{\square}$ & FSTL3 $\boldsymbol{\nabla}$ & $L H F P \triangle$ & NUMA1 $\bullet$ & $S F P Q \square$ & $Z N F 384^{\mathrm{b}} \bullet 0$ \\
\hline CCND2 $\mathbf{\nabla}$ & $F^{\prime} \cup S^{b} \bullet \triangle$ & $L H X 4^{\mathrm{b}} \bigcirc$ & NUP98 $\bullet \bigcirc \wedge$ & SFRS3 $\mathbf{\nabla}$ & $Z N F N 1 A 1^{\mathrm{b}} \boldsymbol{\nabla}$ \\
\hline CCND3 $\mathbf{\nabla}$ & FVT1 $\boldsymbol{\nabla}$ & LIFR $\square$ & $N U P 214 \bullet \bigcirc \bigcirc \wedge$ & $S H 3 G L 1 \bullet$ & \\
\hline CDK6 $\mathbf{\nabla}$ & GAS $7 \mathrm{~b}$ & $\angle M O 1^{\mathrm{b}}$ & NUT $\square$ & $S I L O$ & \\
\hline CDKN2A \ & GMPS $\bullet$ & $\angle M O 2^{\mathrm{b}}$ & ODZ4 $\square$ & $\operatorname{SS} 18^{\mathrm{b}} \triangle$ & \\
\hline$C D \times 2^{b} \bullet$ & GOLGA5 $\square$ & $L P P \diamond \triangle$ & $O L I G 2^{\mathrm{b}}$ & $S S 18 L 1^{b} \triangle$ & \\
\hline CEP1 $\bigcirc$ & GOPC $\triangle$ & $\angle Y L 1^{\mathrm{b}}$ & PAFAH1B2 $\mathbf{\nabla}$ & $S S H 3 B P 1 \bullet$ & \\
\hline $\mathrm{CHIC2} \bullet$ & GPHN & $M A F^{D} \square$ & $P A X 3^{b} \triangle$ & $S S X 1^{\mathrm{b}} \triangle$ & \\
\hline$C L T C \diamond \triangle$ & GR6 & $M A F B^{\mathrm{b}} \square$ & $P A X 5^{b} \bigcirc \nabla$ & $S S \times 2^{\mathrm{b}} \triangle$ & \\
\hline
\end{tabular}

${ }^{a}$ Genes encoding tyrosine kinases. ${ }^{\mathrm{b}}$ Transcription control genes.

For abbreviations, see Table 1. 


\section{Implications}

Our results support the unorthodox concept that cytogenetic aberrations resulting in deregulated or rearranged genes may be of greater importance as an initial step in epithelial tumorigenesis than generally believed. Admittedly, there are quantitative differences; the fraction of epithelial tumors characterized by balanced aberrations is much smaller than that of, for example, the hematological disorders. Thus, the frequency of such abnormalities among all unselected epithelial tumors is only $3 \%$ but is $19 \%$ and $29 \%$ among mesenchymal tumors and AML, respectively (data not shown). This discrepancy is, to a large extent, due to the fact that a few aberrations among the latter neoplastic disorders are very common, whereas most are as rare as those identified in epithelial tumors. For example, the three dominating abnormalities in AML, $\mathrm{t}(8 ; 21)(\mathrm{q} 22 ; \mathrm{q} 22), \mathrm{t}(15 ; 17)(\mathrm{q} 22 ; \mathrm{q} 12)$ and $\operatorname{inv}(16)(\mathrm{p} 13 \mathrm{q} 22)$, constitute $65 \%$ of unselected cases having a recurrent balanced aberration (data not shown). Such common changes may exist also among epithelial tumors but have not yet been detected, owing to the small number of cases so far studied within each of the many different tumor entities. Alternatively, and more probably, epithelial tumors may be characterized by numerous, but individually rare, pathogenetically important gene rearrangements that have not yet been identified. Some of these may even be submicroscopic ${ }^{23,24}$. Considering that malignant epithelial tumors represent the dominating cause of human cancer morbidity and mortality, the implications are not trivial, especially in view of recent progress in the development of treatment regimens specifically directed against the products of the pathogenetic gene fusions in malignant disorders ${ }^{25,26}$.

URL. The Mitelman Database of Chromosome Aberrations in Cancer is available at http://cgap.nci.nih.gov/Chromosomes/Mitelman.

\section{ACKNOWLEDGMENTS}

This work was supported by the Swedish Cancer Society and the Swedish Children's Cancer Foundation.

\section{COMPETING INTERESTS STATEMENT}

The authors declare that they have no competing financial interests.

Received 22 December 2003; accepted 11 February 2004

Published online at http://www.nature.com/naturegenetics/
1. Heim, S. \& Mitelman, F. Cancer Cytogenetics 2nd edn. (Wiley-Liss, New York, 1995).

2. Mitelman, F., Mertens, F. \& Johansson, B. A breakpoint map of recurrent chromosomal rearrangements in human neoplasia. Nat. Genet. 15, 417-474 (1997).

3. Rabbitts, T.H. Chromosomal translocations in human cancer. Nature 372, 143-149 (1994).

4. Look, A.T. Oncogenic transcription factors in human acute leukemias. Science $\mathbf{2 7 8}$ 1059-1064 (1997).

5. Rowley, J.D. Chromosomal translocations: dangerous liaisons revisited. Nat. Rev. Cancer 1, 245-250 (2001).

6. Helman, L.J. \& Meltzer, P. Mechanisms of sarcoma development. Nat. Rev. Cancer 3 , 685-694 (2003)

7. Mertens, F., Johansson, B., Höglund, M. \& Mitelman, F. Chromosomal imbalance maps of malignant solid tumors: a cytogenetic survey of 3185 neoplasms. Cancer Res. 57, 2765-2780 (1997).

8. Albertson, D.G., Collins, C., McCormick, F. \& Gray, J.W. Chromosome aberrations in solid tumors. Nat. Genet. 34, 369-376 (2003).

9. Eguchi, M. et al. Fusion of ETV6 to neurotrophin-3 receptor TRKC in acute myeloid leukemia with $\mathrm{t}(12 ; 15)(\mathrm{p} 13 ; \mathrm{q} 25)$. Blood 93, 1355-1363 (1999).

10. Knezevich, S.R., McFadden, D.E., Tao, W., Lim, J.F. \& Sorensen, P.H.B. A novel ETV6NTRK3 gene fusion in congenital fibrosarcoma. Nat. Genet. 18, 184-187 (1998).

11. Rubin, B.P. et al. Congenital mesoblastic nephroma $t(12 ; 15)$ is associated with ETV6-NTRK3 gene fusion. Cytogenetic and molecular relationship to congenital (infantile) fibrosarcoma. Am. J. Pathol. 153, 1451-1458 (1998).

12. Tognon, C. et al. Expression of the ETV6-NTRK3 gene fusion as a primary event in human secretory breast carcinoma. Cancer Cel/ 2, 367-376 (2002).

13. Nowell, P.C. The clonal evolution of tumor cell populations. Science 194, 23-28 (1976).

14. Hanahan, D. \& Weinberg R.A. The hallmarks of cancer. Cell 100, 57-70 (2000).

15. Loeb, L.A., Loeb, K.R. \& Anderson, J.P. Multiple mutations and cancer. Proc. Natl. Acad. Sci. USA 100, 776-781 (2003).

16. Lengauer, C., Kinzler, K.W. \& Vogelstein, B. Genetic instabilities in human cancers. Nature 396, 643-649 (1998).

17. Nowak, M.A. et al. The role of chromosomal instability in tumor initiation. Proc. Natl. Acad. Sci. USA 99, 16226-16231 (2002)

18. Sieber, O.M., Heinimann, K. \& Tomlinson, I.P.M. Genomic instability - the engine of tumorigenesis? Nat. Rev. Cancer 3, 701-708 (2003).

19. Knudson, A.G. Two genetic hits (more or less) to cancer. Nat. Rev. Cancer 1, 157-170 (2001).

20. Lengauer, C. How do tumors make ends? Proc. Natl. Acad. Sci. USA 98 12331-12333 (2001).

21. Heim, S., Mandahl, N. \& Mitelman, F. Genetic convergence and divergence in tumor progression. Cancer Res. 48, 5911-5916 (1988).

22. Gorunova, L. et al. Cytogenetic analysis of pancreatic carcinomas: intratumor heterogeneity and nonrandom pattern of chromosome aberrations. Genes Chromosomes Cancer 23, 81-99 (1998).

23. Romana, S.P. et al. The $\mathrm{t}(12 ; 21)$ of acute lymphoblastic leukemia results in a telAML1 gene fusion. Blood 85, 3662-3670 (1995).

24. Golub, T.R. et al. Fusion of the TEL gene on $12 \mathrm{p} 13$ to the AML1 gene on $21 \mathrm{q} 22$ in acute lymphoblastic leukemia. Proc. Natl. Acad. Sci. USA 92, 4917-4921 (1995).

25. Druker, B.J. Inhibition of the Bcr-Abl tyrosine kinase as a therapeutic strategy for CML. Oncogene 21, 8541-8546 (2002).

26. Rabbitts, T.H. \& Stocks, M.R. Chromosomal translocation products engender new intracellular therapeutic technologies. Nat. Med. 9, 383-386 (2003). 